\title{
Preface to the Special Issue on "Innovative Applications of Radar and LiDAR Remote Sensing”
}

\author{
Peter Tian-Yuan Shih ${ }^{1, *}$, Yi-Hsing Tseng ${ }^{2}$, Fuan Tsai ${ }^{3}$, and Chung-Pai Chang ${ }^{3}$ \\ ${ }^{I}$ Department of Civil Engineering, National Chiao Tung University, Hsinchu, Taiwan, R.O.C. \\ ${ }^{2}$ Department of Geomatics, National Cheng Kung University, Tainan City, Taiwan, R.O.C. \\ ${ }^{3}$ Center for Space and Remote Sensing Research, National Central University, Taoyuan City, Taiwan, R.O.C.
}

Received 7 July 2016, accepted 11 August 2016

Citation: Shih, P. T. Y., Y. H. Tseng, F. Tsai, and C. P. Chang, 2016: Preface to the special issue on "innovative applications of radar and LiDAR remote sensing". Terr. Atmos. Ocean. Sci., 27, I-II, doi: 10.3319/TAO.2016.08.11.01(ISRS)

Radar (radio detection and ranging) and LiDAR (light detection and ranging) are active remote sensing techniques that can be operated day or night. They send out a signal and receive backscattered or reflected signals from ground surface features to form image data. Radar uses relatively long wavelengths which allows these systems to "see" through clouds, smoke, and some vegetation. LiDAR is a laser scanning system that allows for the high accuracy measurement of 3D object surfaces. Innovative radar and LiDAR remote sensing applications have been continuously developed and carried forward in many fields. For example, radar imagery is widely applied in crop monitoring, flood mapping, soil moisture mapping, forestry biomass estimation, terrain analysis, oil spill detection, and snow/ice mapping. LiDAR data are used increasingly to generate digital terrain models (DTMs), 3D city modeling, forest structure investigation, geological analysis, coastal zone, and bathymetric mapping etc. This special issue promotes innovative radar and LiDAR remote sensing applications.

This TAO special issue is associated with the $22^{\text {nd }} \mathrm{In}$ ternational Symposium on Remote Sensing (ISRS 2015), which was held 22 - 24 April 2015 in Tainan, Taiwan. Since 2012 the ISRS symposium series has officially been co-organized annually by three societies: the Korean Society of Remote Sensing (KSRS), Remote Sensing Society of Japan (RSSJ), and Chinese Society of Photogrammetry and Remote Sensing (CSPRS). ISRS has become the most prominent remote sensing symposium in East Asia and also one of the most successful symposiums co-organized by the three academic societies. More than 330 participants from 14 countries attended ISRS 2015. In total, 228 papers were presented in 36 oral and 2 poster sessions, which covered a

\footnotetext{
* Corresponding author

E-mail:tyshih@mail.nctu.edu.tw
}

wide range of remote sensing fields.

This special issue has been specifically arranged to cover the innovative applications of radar and LiDAR remote sensing. We received 21 manuscripts in total for this special issue. After a careful review process 12 papers were accepted for publication. The papers presented in this special issue include the following topics:

\section{Radar Remote Sensing:}

(1) Small ship detection and inspection using RADARSAT-2 SAR data (Jeong and Yang 2016).

(2) Large scale flooding detection using PALSAR and AMSR-E data (Li and Takeuchi 2016).

(3) InSAR and survey data fusion to improve land subsidence monitoring resolution in the Choushui river fluvial plain, Taiwan (Lu et al. 2016).

(4) Hybrid parallel computing for satellite SAR image processing (Sun et al. 2016).

\section{LiDAR Remote Sensing:}

(1) Detecting ice margins of the Antarctic ice shelf using ICESat laser altimetry (Kim et al. 2016b).

(2) Above-ground biomass estimation of a logged-over lowland rainforest in Sabah, Malaysia using airborne LiDAR data (Phua et al. 2016).

(3) Object-based land cover classification using airborne LiDAR and spectral images (Teo and Huang 2016).

(4) Mapping CHM and LAI for heterogeneous forests using airborne full-waveform LiDAR data (Tseng et al. 2016).

(5) Individual tree position and height detection using airborne LiDAR data (Kim et al. 2016a).

(6) Full-waveform LiDAR point cloud land cover classification with volumetric texture measures (Tsai et al. 2016).

(7) Bathymetric LiDAR green channel derived reflectance 
in the Dongsha 2010 mission (Lin et al. 2016).

(8) Geomorphological change detection using an integrated method on the Taan River Watershed, Taiwan (Wu et al. 2016).

We acknowledge all of the authors for contributing papers to this special issue. We also sincerely appreciate all reviewers for their time, efforts, and valuable comments to ensure paper quality. We also thank the administrative assistance provided by the TAO office for smoothing the reviewing process.

\section{REFERENCES}

Jeong, J. and C. S. Yang, 2016: Automatic image contrast enhancement for small ship detection and inspection using RADARSAT-2 synthetic aperture radar data. Terr. Atmos. Ocean. Sci., 27, 463-472, doi: 10.3319/ TAO.2016.01.01.01(ISRS). [Link]

Kim, E., W. K. Lee, M. Yoon, J. Y. Lee, E. J. Lee, and J. Moon, 2016a: Detecting individual tree position and height using Airborne LiDAR data in Chollipo Arboretum, South Korea. Terr. Atmos. Ocean. Sci., 27, 593604, doi: 10.3319/TAO.2016.03.29.01(ISRS). [Link]

Kim, J., J. Yu, L. Wang, H. Liu, and H. Shin, 2016b: Morphological characteristics of the ice margins of Antarctic ice shelf and outlet glacier extracted from ICESat laser altimetry along-track profiles. Terr. Atmos. Ocean. Sci., 27, 451-462, doi: 10.3319/TAO.2015.12.24.01(ISRS). [Link]

Li, X. and W. Takeuchi, 2016: Land surface water coverage estimation with PALSAR and AMSR-E for large scale flooding detection. Terr. Atmos. Ocean. Sci., 27, 473480, doi: 10.3319/TAO.2016.01.06.01(ISRS). [Link]

Lin, W. T., P. T. Y. Shih, J. C. Chen, and C. J. Liao, 2016: Bathymetric LiDAR green channel derived reflectance: An experiment from the Dongsha 2010 mission.
Terr. Atmos. Ocean. Sci., 27, 565-576, doi: 10.3319/ TAO.2016.02.19.02(ISRS). [Link]

Lu, C. H., C. F. Ni, C. P. Chang, Y. A. Chen, and J. Y. Yen, 2016: Geostatistical data fusion of multiple type observations to improve land subsidence monitoring resolution in the Choushui River Fluvial Plain, Taiwan. Terr. Atmos. Ocean. Sci., 27, 505-520, doi: 10.3319/ TAO.2016.01.29.02(ISRS). [Link]

Phua, M. H., S. W. Hue, K. Ioki, M. Hashim, K. Bidin, B. Musta, M. Suleiman, S. W. Yap, and C. R. Maycock, 2016: Estimating logged-over lowland rainforest above-ground biomass in Sabah, Malaysia using airborne LiDAR data. Terr. Atmos. Ocean. Sci., 27, 481489, doi: 10.3319/TAO.2016.01.06.02(ISRS). [Link]

Sun, C. L., L. C. Tsai, and C. Y. Chiang, 2016: SAR image simulations using the LBM algorithm on MPI-GPU. Terr. Atmos. Ocean. Sci., 27, 577-592, doi: 10.3319/ TAO.2016.03.10.01(ISRS). [Link]

Teo, T. A. and C. H. Huang, 2016: Object-based land cover classification using airborne lidar and different spectral images. Terr. Atmos. Ocean. Sci., 27, 491-504, doi: 10.3319/TAO.2016.01.29.01(ISRS). [Link]

Tsai, F., J. S. Lai, and Y. H. Lu, 2016: Full-Waveform LiDAR point cloud land cover classification with volumetric texture measures. Terr. Atmos. Ocean. Sci., 27, 549-563, doi: 10.3319/TAO.2016.02.19.01(ISRS). [Link]

Tseng, Y. H., L. P. Lin, and C. K. Wang, 2016: Mapping CHM and LAI for heterogeneous forests using airborne full-waveform LiDAR data. Terr. Atmos. Ocean. Sci., 27, 537-548, doi: 10.3319/TAO.2016.01.29.04(ISRS). [Link]

Wu, J. Y., T. A. Teo, and P. T. Y. Shih, 2016: Geomorphological change detection using an integrated method: A case study on the Taan River watershed, Taiwan. Terr. Atmos. Ocean. Sci., 27, 521-536, doi: 10.3319/ TAO.2016.01.29.03(ISRS). [Link] 